\title{
A Study on the Peak Separation of Acetone and Acrolein Based on High-Performance Liquid Chromatography (HPLC) Method
}

\author{
Shin-Do Kim, Chang-Hwan Kim, Jin-Su Pak, ${ }^{\dagger}$ and Jeong-Joo Lee ${ }^{\ddagger}$ \\ Department of Environmental Engineering, University of Seoul. Seoul 130-7+3. Korea. E-mail: moguaiohanmail.net \\ -Global Enwironment Research Center, National Institute Enironmental Research, Baengmeong-myeon. \\ Ongin-gun, Incheon 409-911. Korea \\ ${ }^{\ddagger}$ Deparment of Occupational and Environmental Health, Yongin Lniversity, Yongin-si, Gveonggi-do 4+9-714, Korea \\ Received January 22, 2009. Accepted July 22, 2009
}

\begin{abstract}
To resolve the differentiation problem of acetone and acrolein in the analysis of carbonyls by high-perfomance liquid chromatography (HPLC), we investigated the optimum analytical conditions for their separation. Carbonyl compounds were collected by 2,4-dinitrophenylhydrazine (DNPH)-coated cartridges. We examined the influence of three experimental variables: temperature $\left(25,30,40,50\right.$ and $\left.60^{\circ} \mathrm{C}\right)$, flow rate (1.0 and $1.2 \mathrm{~mL} / \mathrm{min}$ ), and relative mobile phase composition (among acetonitrile, water and tetrahydrofuran). The experimental results revealed the optimum analy tical condition of a flow rate of $1.2 \mathrm{~mL} / \mathrm{min}$, temperature of 32 " $\mathrm{C}$ and mobile phase composition of acetonitrile: water: tetrahydrofuran $=34: 52.8: 13.2$. The analy sis of indoor air composition indicated that acrolein and acetone comprised $11 \%$ and $42 \%$ of all aldehydes, respectively.
\end{abstract}

Key Words: Acetone, Acrolein. Tetrahydrofuran. Peak separation, HPLC

\section{Introduction}

People in modern society tend to spend most of their time indoors. As a result the demand for advanced building materials and living supplies is increasing. with the potential for the release of harmful toxic compounds directly or indirectly into the living environment. Since these materials tend to be the sources of such harnful substances, indoor air pollution should be considered a threat to human health. even at low concentrations. ${ }^{1}$

Formaldehyde is recognized as the most probable carcinogenic source in indoor environments. ${ }^{2}$ For example formaldehyde is the source of carbonyl compounds, which are usually generated indoors from construction materials. furniture or smoking. ${ }^{3+4}$ Carbonyl compounds have different characteristics of molecular structure, solubility. chemical reaction and toxicity. Many kinds of carbonyl compound are receptive and are known to stimulate the upper airway's mucosa, visual nerve and the skin. ${ }^{5}$ In particular. formaldehyde and acrolein are known to be highly stimulatory, even at low concentration. ${ }^{6}$

Acrolein is classified as a highly toxic substance that causes severe irritation of the mucous membrane. lungs. and skin. EPA integrated risk information system (IRIS) has classified acrolein in Group C. i.e.. a potential carcinogen. Acetone can cause breathing problems, pain of the pleura. pulmonary edema, hypoxia bronchospasm. continuous decline of the lung function cellulites when exposed to skin, sepsis, contracture. addiction. and osteomyelitis. ${ }^{5}$ Exposure to the eyes can induce a burn and festering of the cornea. Oral exposure can lead to a burn of the gullet, a burn of the stomach pyloristenosis, and gastrointestinal burns.

Korea's indoor air standard standards currently mandate the measurement and management of only formaldehyde among all the carbonyl compounds. whereas most carbony ls are regulated by the standard of odor regulations of working environments. Extensive research has been conducted on formaldehy'de in indoor air, but not on carbonyls.

Acrolein and acetone. when analyzed by high-performance liquid chromatography (HPLC), are difficult to differentiate from the analy sis of fixed quantity. due to their similar amounts of molecules and retention times (RT). Therefore. the concentrations of other substances can be misinterpreted or even excluded. This study investigates the characteristics of acetone and acrolein with the goal of determining the optimum analytical conditions for their separation by examining the influence of temperature, flow rate, and relative mobile phase composition.

\section{Experimental method}

Analytical conditions of HPLC. In this study. an HPLC system (600s model: Waters Corporation. USA) equipped with a Waters 616 punp and a Waters 486 detector (UV/Vis) was used to analyze the carbonyl compounds along with a MIDAS auto sampler. The analytical conditions of HPLC are indicated in Table 1.

Mobile solvent was used by mixing acetonitrile and water (Mix A). or acetonitrile, water and tetrahydrofuran (THF) (Mix B) in isocratic mode. THF was mixed with water at the ratio of $20: 80$. This mixture was used after 24 lur stabilization. An LC- 18 column $(5 \mu \mathrm{m} \times 25 \mathrm{~cm} \times 4.6 \mathrm{~mm})$ was used. The detected wavelength was fixed at $360 \mathrm{~nm}$. The flow rate of the mobile phase was operated at either 1.0 or $1.2 \mathrm{~mL} / \mathrm{min}$.

Separations of acetone and aciolein. The experiment was conducted by varying the flow rate, relative composition of the mobile phase and temperature. Mix A included 5 different ratios of acetonitrile to water in the mobile phase ((1) $20: 80$, (2) $30: 70$. (3) $35: 65$. (4) $40: 60$. (5) $50: 50$. (6) $60: 40$ ). Mix $B$ included and fixed up 6 different ratios in the mobile phase (acetonitrile : water : THF $=$ (1) $20: 64: 16$. (2) $30: 56: 14$. 
Table 1. Analy tical Conditions of HPLC

\begin{tabular}{|c|c|}
\hline Item & Analysis Condition \\
\hline Detector & UV/Vis spectrometer (at $360 \mathrm{~mm}$ ) \\
\hline Coluniti & $\begin{array}{l}\text { Supelco LC-18 colmmn } \\
(5 \mu \mathrm{m} \times 25 \mathrm{~cm} \times 4.6 \mathrm{~mm})\end{array}$ \\
\hline Purge gas & $\mathrm{He}(99.999) \%$ \\
\hline Purge gas flow & $100 \mathrm{~mL} / \mathrm{mnint}$ \\
\hline Quantity of Injection & $20 \mu \mathrm{L}$ \\
\hline Run Time & $32 \mathrm{~min}$ \\
\hline Elution mode & Isogratic \\
\hline \multirow[t]{3}{*}{ Mobile Phases } & A: Acetonitrile \\
\hline & B: Water \\
\hline & C: Tetrahydrofuran \\
\hline \multirow[t]{2}{*}{ Mobile Phases rate } & 1) $[\mathrm{Mix} A] \mathrm{A}: \mathrm{B}=20: 80 \sim 80: 20$ \\
\hline & 2) $\begin{array}{r}{[\operatorname{Mix~B]} A: B: C=20: 64: 16 \sim} \\
80: 16: 64\end{array}$ \\
\hline Column Oven Temperature & $25 \sim 60^{\circ} \mathrm{C}$ \\
\hline
\end{tabular}

1) $[\mathrm{Mix} \mathrm{A}] \mathrm{A}: \mathrm{B}=$ Acetonitrile: Water 2) [Mix B] A: $\mathrm{B}: \mathrm{C}=$ Acetonitrile : Water : Tetrahydroturan

(3) $35: 52: 13$, (4) $40: 48: 12$, (5) $50: 40: 10$, (6) $60: 32:$ 8). The optimum condition for peak separation in acetone and acrolein was examined.

Standard solutions (Carb Carbonyl-2.4-dinitrophenyllhydrazine (DNPH) Mix) were purchased from Supelco (Bellefonte. PA. USA). The standard contains the following 7 chemicals and concentrations ( $\mu \mathrm{g} / \mathrm{mL})$ : formaldelyde $(215)$, acetaldehyde (196). acrolein (119), acetone (122). propionaldehy'de (122) butyraldehyde (143) and benzaldehyde (185). Table 2 shows the dilution ratio of the standard solution and aldehyde concentration in proportion to the dilution ratio for the calibration curve.

Measurement and analy sis of the carbonyl compounds are conform to EPA TO-11A methd that DNPH derivatives (reaction product of carbonyl compounds and 2.4-DNPH (2,4-dinitrophenỵllyydrazine)) were analỳzed by HPLC.

DNPH-silica cartridge is coated with high purity refined 2.4-DNPH in length $+\mathrm{cm}$ polyprophỵlen tube (Top trading. Korea). The use of DNPH-coated silica cartridge led to a negative interference on carbonyl concentrations in the presence of ambient ozone. Therefore. cartridge connected to an upstream ozone scrubber (crystalline potassium iodide trap). After collection of the carbonyl compounds on cartridges the
DNPH derivatives were separated by HPLC. and keep in cold storage under $4{ }^{\circ} \mathrm{C}$ until analyzed.

\section{Results and Discussion}

The peaks of acetone and acrolein were not separated in Mix A. However, in Mix B. with the addition of the solvent THF, the acetone and acrolein peaks could be completely separated according to the conditions.

Calibration standaud check and detection limit. Figure I shows optimun calibration curves when Mixes A and B were used as a mobile phases. The calibration curve was made from 5 -step dilution methods ( $1 / 200$ to $1 / 4000$ ). Table 3 presents the slope of the calibration curve. $\mathrm{R}^{2}$. and the standard deviation values. The slope of Mix A was slightly higher than that of Mix B. and both mixtures showed $\mathrm{R}^{2}(0.997)$.

The reproducibility was evaluated for RT (Ed-this abbrevia-
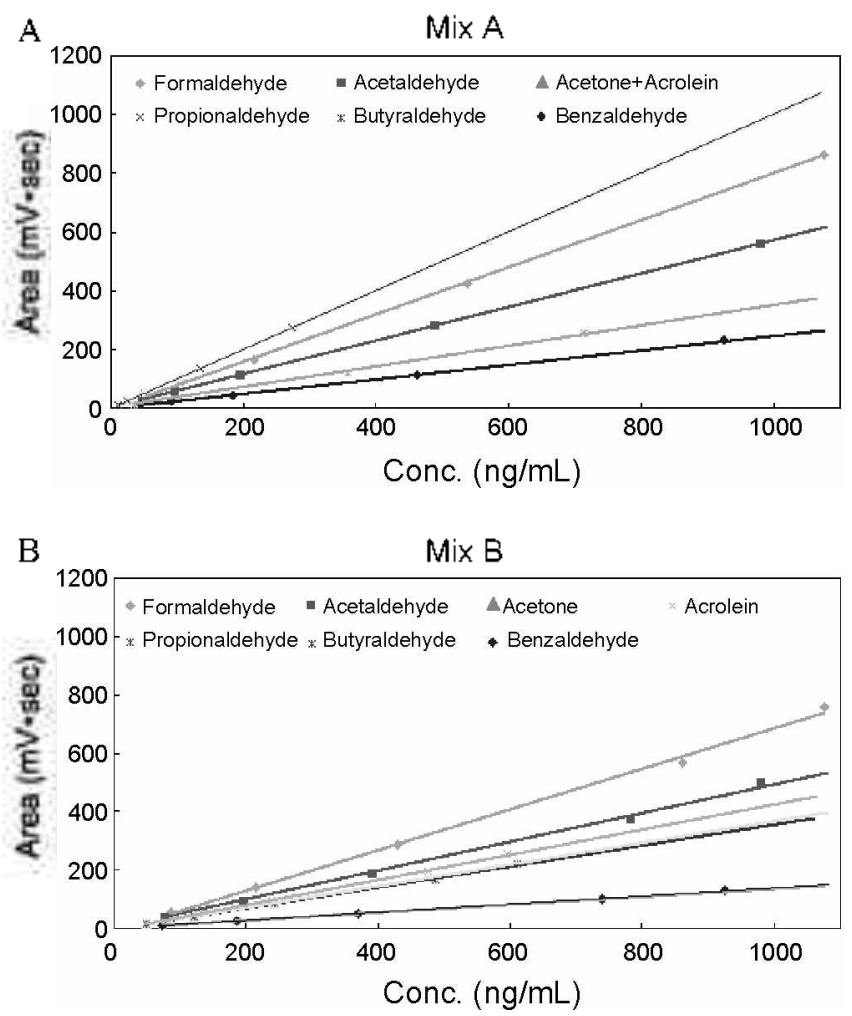

Figure 1. Standard calibration curves of carbonyl compounds for HPLC analysis.

Table 2. Preparation of working standards

\begin{tabular}{|c|c|c|c|c|c|c|c|c|}
\hline \multirow{2}{*}{ Dilution Factor } & \multirow{2}{*}{$\begin{array}{c}\text { Primary Standard } \\
\text { ng } \mathrm{mL}^{-3}\end{array}$} & \multicolumn{7}{|c|}{ Working Standard (ng/mL) } \\
\hline & & 200 & 250 & 400 & 500 & 1,000 & 2,500 & 4,000 \\
\hline Formaldehyde & 215000 & 1,075 & 860 & 537.5 & 430 & 215 & 86 & 53.75 \\
\hline Acetaldehyde & 196000 & 980 & 784 & 490 & 392 & 196 & 78.4 & 49 \\
\hline Acetone & 122000 & 610 & 488 & 305 & 244 & 122 & 48.8 & 30.5 \\
\hline Acrolein & 119000 & 595 & 476 & 297.5 & 238 & 119 & 47.6 & 29.75 \\
\hline Propionaldehyde & 122000 & 610 & 488 & 305 & 244 & 122 & 48.8 & 30.5 \\
\hline Butyraldehyde & 143000 & 715 & 572 & 357.5 & 286 & 143 & 57.2 & 35.75 \\
\hline Bencaldelyyde & 185000 & 925 & 740 & 462.5 & 370 & 185 & 74 & 46.25 \\
\hline
\end{tabular}


Table 3. Slopes and detennination coefficients of the standard calibration chrves for HPLC analysis

\begin{tabular}{|c|c|c|c|c|c|c|c|c|}
\hline & \multicolumn{4}{|c|}{ Calibration slope values } & \multicolumn{4}{|c|}{ Determination coefficients $\left(\mathrm{R}^{2}\right)$} \\
\hline & Exp 1 & Exp 2 & Exp 3 & Average & Exp I & Exp 2 & Exp 3 & Average \\
\hline \multicolumn{9}{|l|}{ 1. Mix A } \\
\hline Fonmaldehyde & 0.803 & 0.806 & 0.784 & 0.798 & 0.9994 & 0.9994 & 0.9999 & 1.000 \\
\hline Acetaldehyde & 0.585 & 0.586 & 0.570 & 0.580 & 0.9995 & 0.9993 & 0.9999 & 1.000 \\
\hline Acetone & 0.472 & 0.474 & 0.462 & 0.469 & 0.9994 & 0.9989 & 0.9996 & 0.999 \\
\hline Acrolein & 0.472 & 0.474 & 0.462 & 0.469 & 0.9994 & 0.9989 & 0.9996 & 0.999 \\
\hline Propionaldehyde & 0.446 & 0.449 & 0.438 & 0.444 & 0.9991 & 0.9986 & 0.9994 & 0.999 \\
\hline Butyraldehyde & 0.353 & 0.356 & 0.345 & 0.352 & 0.9970 & 0.9968 & 0.9990 & 0.998 \\
\hline Benzaldehyde & 0.247 & 0.248 & 0.240 & 0.245 & 0.9980 & 0.9966 & 0.9978 & 0.997 \\
\hline \multicolumn{9}{|l|}{ 2. Mis B } \\
\hline Fonnaldehyde & 0.692 & 0.685 & 0.679 & 0.685 & 0.9982 & 0.9941 & 0.9975 & 0.997 \\
\hline Acetaldelnyde & 0.498 & 0.193 & 0.486 & 0.392 & 0.9982 & 0.9948 & 0.9973 & 0.997 \\
\hline Acetone & 0.363 & 0.362 & 0.360 & 0.362 & 0.9984 & 0.9958 & 0.9982 & 0.997 \\
\hline Acrolein & 0.424 & 0.418 & 0.417 & 0.420 & 0.9984 & 0.9979 & 0.9974 & 0.998 \\
\hline Propionaldehyde & 0.361 & 0.353 & 0.349 & 0.354 & 0.9977 & 0.9950 & 0.9968 & 0.997 \\
\hline Butyraldehyde & 0.254 & 0.243 & 0.250 & 0.249 & 0.9923 & 0.9864 & 0.9984 & 0.992 \\
\hline Benzaldeliyde & 0.135 & 0.138 & 0.136 & 0.136 & 0.9974 & 0.9978 & 0.9964 & 0.997 \\
\hline
\end{tabular}

Table 4. The fundamental quality assurance for carbonyl conpounds analysis by the HPLC method

[A] Reproducibility of carbonyl compounds analysis by HPLC $(\mathrm{n}=3)$

\begin{tabular}{|c|c|c|c|c|}
\hline \multirow{3}{*}{ Carbonyl compounds } & \multicolumn{4}{|c|}{ Reproducibility (RSD\%) } \\
\hline & \multicolumn{2}{|c|}{ RT } & \multicolumn{2}{|c|}{ Calibration Slope } \\
\hline & Mix $A^{l y}$ & $\operatorname{Mix} B^{2)}$ & $\operatorname{Mix} A^{17}$ & $\operatorname{Mix}^{21}$ \\
\hline Formaldehyde & 0.972 & 1.176 & 1.491 & 0.256 \\
\hline Acetaldehyde & 1.150 & 1.256 & 1.540 & 0.333 \\
\hline Acrolein & 0.441 & 1.542 & 1.435 & 0.261 \\
\hline Acetone & 0.960 & 1.529 & 1.435 & 0.261 \\
\hline Propionaldehyde & 1.700 & 1.469 & 1.349 & 0.407 \\
\hline Butỵaldehyde & 2.133 & 1.646 & 1.601 & 0.480 \\
\hline Benzaldehyde & 1.074 & 1.983 & 1.812 & 0.606 \\
\hline
\end{tabular}

1) Mix $A=A C N$ : Water: $\mathrm{THF}=60: 40: 0$ and 2) Mix $B=A C N$ : Water : $\mathrm{THF}=34: 51.2: 12.8$

[B] Minimunn detection linit of carbonyl compounds analyzed by HPLC

\begin{tabular}{|c|c|c|c|c|}
\hline \multirow[t]{2}{*}{ Carbonyl compounds } & \multirow{2}{*}{$\begin{array}{c}\text { Liq } \\
\text { concen- } \\
\text { tration }\end{array}$} & \multirow{2}{*}{$\frac{\begin{array}{c}\text { Absolute } \\
\text { mass }^{\sigma}\end{array}}{\operatorname{ng}}$} & \multicolumn{2}{|c|}{ Concentration $^{b}$} \\
\hline & & & $\mu g / \mathrm{m}^{3}$ & ppbv \\
\hline \multicolumn{5}{|l|}{ 1. $\mathrm{Mix} \mathrm{A}$} \\
\hline Fonmaldehyde & 2.909 & 0.058 & 0.808 & 0.641 \\
\hline Acetaldehyde & 4.423 & 0.088 & 1.229 & 0.670 \\
\hline Acetone+Acrolen & 3.807 & 0.076 & 1.058 & 0.438 \\
\hline Propionaldehyde & 9.557 & 0.191 & 2.655 & 1.099 \\
\hline Butyraldehyde & 7.001 & 0.140 & 1.945 & 0.648 \\
\hline Benzaldehyde & 13.265 & 0.265 & 3.685 & 0.836 \\
\hline \multicolumn{5}{|l|}{ 2. Mix B } \\
\hline Formaldehyde & 1.066 & 0.021 & 0.296 & 0.235 \\
\hline Acetaldehyde & 2.769 & 0.055 & 0.769 & 0.420 \\
\hline Acetone & 2.482 & 0.050 & 0.689 & 0.285 \\
\hline Acrolein & 3.295 & 0.066 & 0.915 & 0.392 \\
\hline Propionaldehyde & 3.881 & 0.078 & 0.078 & 0.446 \\
\hline Butyraldehyde & 2.684 & 0.054 & 0.746 & 0.249 \\
\hline Benzaldehyde & 7.033 & 0.141 & 1.954 & 0.443 \\
\hline
\end{tabular}

${ }^{2}$ Estimated from $20 \mu \mathrm{L}$ sample injection. "ug $\mathrm{m}^{3}$ is estimated by: sampling volume of $18 \mathrm{~L}$ and extraction volume of $5 \mathrm{~mL}$, and ppby is derived by assuming at $25^{\circ} \mathrm{C}$ and $\mathrm{l}$ atm pressure tion has already been defined above) and calibration slope. which represent the punp performance, to check the level of the errors incurred during the process of aldehyde chemicals analysis. After standard solutions were diluted at $1 \mathrm{mg} / \mathrm{L}$, the relative standard deviations (RSD) were evaluated using the results analyzed in triplicate (Table 4(a)). The RSD values of Mixes A and B for peak RT and calibration slope were $1.9 \%$ and $2.2 \%$, respectively. The method detection limit (MDL) of the aldelyydes was calculated by nultiplying the standard deviation of the diluted standard concentration by 3.14 -fold in order to reach the detection limit (DL) level ( $1 / 4,000$ concentration of standard stock solution). This standard sample analysis process was conducted seven times. The chemical concentrations ( $\mathrm{ng} / \mathrm{nL}$ ) in Mixes A and B were formaldehyde (0.9.0.3). acetaldelyde $(1.4,0.9)$, acetone (1.2, 0.8), acrolein (1.2, 1.0). propionaldehyde (3.0. 1.2), butyraldehyde $(2.2,0.9)$, and benzaldelyde $(4.2 .2 .2)$, respectively

Table 4 (b) shows the DL for the aldehyde chemicals of the liquid samples and ambient air concentration based on an actual air sample of $18 \mathrm{~L}$. The reproducibility of Mixes A and $B$ indicated that the RSD of RT was more favorable in the case of Mix A than Mix B, while the reverse was true for the RSD of the linear calibration curve. The MDL of Mix B was lower than that of Mix A.

Peak separation by temperatue condition. Firstly. the temperature $\left(25-60^{\circ} \mathrm{C}\right)$. and nobile phase composition were controlled equally for both $\mathrm{A}$ and $\mathrm{B}$. while the reproducibility of the peak separation was investigated. With Mix A. peak separation didn't occur in any condition. whereas the peaks were separated with reproducibility wa the appropriate control of temperature. flow rate. and nobile phase composition with Mix B.

Peak separation by mobile phase condition. Mix A condition (Acetonitrile + Water): Figure 2 shows the chronatography results with Mix A. Figure 2 (a) presents the chromatogram of the standard samples analyzed under HPLC. a method often used as to analyze the general indoor air quality in Korea. The peaks of acetone (\#3) and acrolein (\#4) were overlapped.

Figure 2(b) $\sim 2$ (d) presents a typical case of the altered 
a) Acetonitrile-Water $(60: 40)$ at $1.0 \mathrm{~mL} / \mathrm{min}, 25^{\circ} \mathrm{C}$

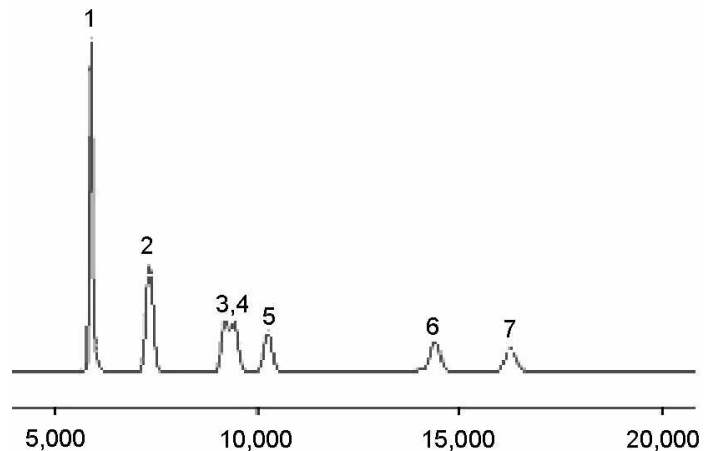

b) Acetonitrile-Water $(60: 40)$ ) at $1.0 \mathrm{~mL} / \mathrm{min}, 60^{\circ} \mathrm{C}$

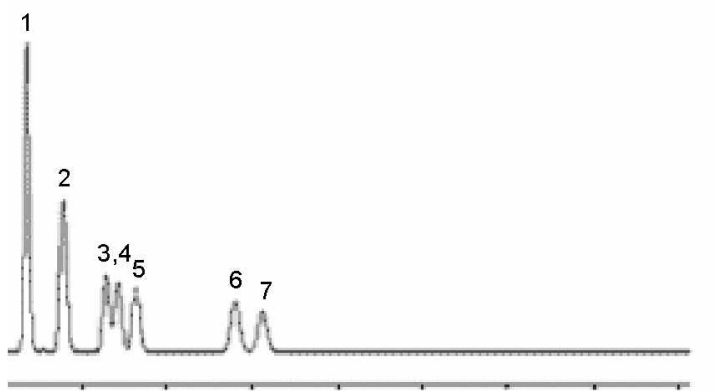

$6,000 \quad 8,000 \quad 10,000 \quad 12,000 \quad 14,000 \quad 16,000 \quad 18,000 \quad 20,000$

c) Acetonitrile-Water $\left(80: 20\right.$ ) at $1.0 \mathrm{~mL} / \mathrm{min}, 25^{\circ} \mathrm{C}$

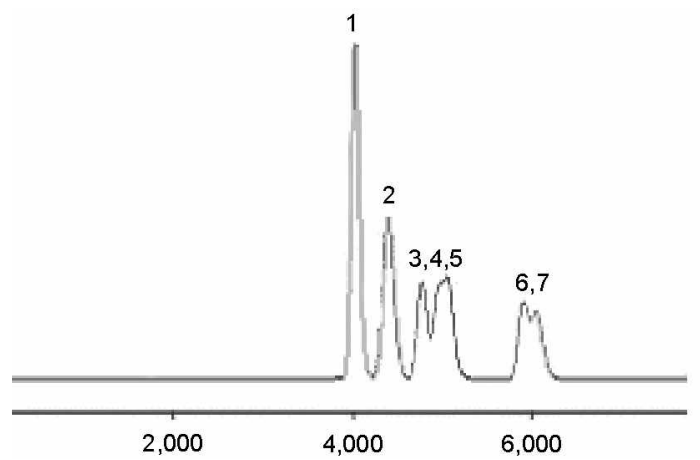

d) Acetonitrile-Water ( $40: 60$ ) at $1.0 \mathrm{~mL} / \mathrm{min}, 25^{\circ} \mathrm{C}$

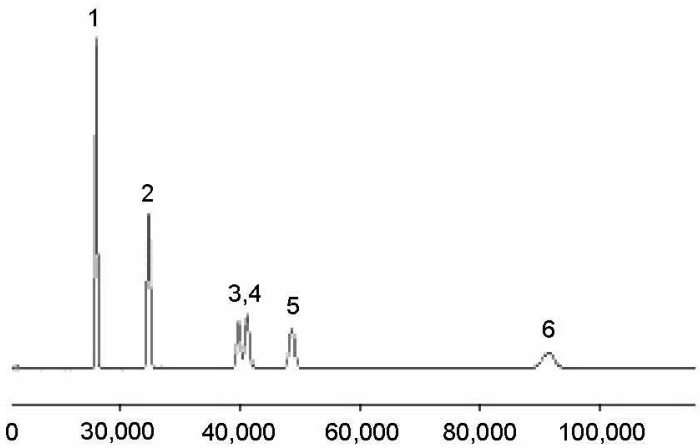

1. Formaldelyde, 2. Acetaldehyde, 3. Acrolein, 4. Acetone.

5. Propionaldehyde. 6. Butyraldelyyde. 7. Benzaldehyde

Figure 2. Chromatogram obtained from a standard solution of carbonyl compounds by Mix A types (Acetonitrile + Water). analytical condition of Figure 2(a). When temperature was higher than of the Figure 2(a) condition, peak separation performance improved. although complete peak isolation was not possible. When the composition rate of acetonitrile was too high (Figure 2(c)), peaks that had been previously isolated became overlapped due to the short RT. With increasing water rate (Figure 2(d)), the analy sis process was not completed and the two peaks were not isolated in spite of the expanded RT to $120 \mathrm{~min}$.

As mentioned above. the non-isolated peaks of acetone and acrolein prevent objective analysis of the HPLC findings, depending on individuals. Furthermore identifying the status of these two substances can be difficult due to their underestimation or overestimation.

Wang et al. presented the results of 13 cigarette smoke samples to optimize the HPLC analytical condition for carbonyl compounds analy sis. The proposed optimum analy tical conditions were Mix A (with a water : acetonitrile : THF : iso-propanol composition of $59: 30: 10: 1$ ) and Mix B (the rate of acetonitrile : water is $65: 35$ ). The efficiency of Mix $\mathrm{B}$ as an efficient analytical condition was not ascertained due to insufficient graphs and explanations. while Mix A was judged to be efficient. However, Wang et al. 's study did not include temperature, one of the crucial factors in analytical conditions. that also needs to be carefully considered.

Accordingly the present experimental focus on the mobile phase composition and column temperature profile has deternuined the optimum HPLC condition. This finding should be useful for other research. In addition. the concentrations of acetone and acrolein. which were not determined through the existing mobile phase method. were compared quantitatively under the optinum condition of the mobile phase composition of acetonitrile. water and THF.

Mix B condition (Acetonitrile+Water +Tetiahydrofuran): Figure 3 represents a chromatogran for Mix B showing that the isolation of acetone and acrolein was done up to the baseline using the three-solvent mobile phase. This separation attributed the result to the improved solubility with the addition of a small amount of THF. leading to minimized RT and the tailing effect.

The sophisticated reproducibility of the resulting chromatogram with the three-solvent mobile phase enabled the optinum condition to be detenmined as follows : acetonitrile : water : THF composition of $34: 52.8: 13.2$. temperature of $32^{\circ} \mathrm{C}$. and flow rate of $1.2 \mathrm{~mL} / \mathrm{min}$. The isolation efficiency of the acetone and acrolein peaks. which couldn t be separated otherwise. was enhanced by the addition of the solvent THF.

Figure 3(b) 3(d) shows the isolation characteristics at the optinum conditions according to the temperature and mobile phase composition matrix. At the Figure 3(a) condition, the RT was shortened with increasing temperature, as was the case in Figure 3(b). but the acetone and acrolein peaks were overlapped again. This resulted from the highly reduced RT due to the excessively ligh acetonitrile composition (Figure 3(c)). Additionally: a higher water composition (Figure $3(\mathrm{~d})$ ) afforded complete peak isolation. while its efficiency decreased due to prolonged analy sis time.

Feng et al perfonmed an experiment on the mobile phase 
a) Acetonitrile-Water-THF (34:52.8:13.2) at $1.2 \mathrm{~mL} / \mathrm{min}, 32^{\circ} \mathrm{C}$

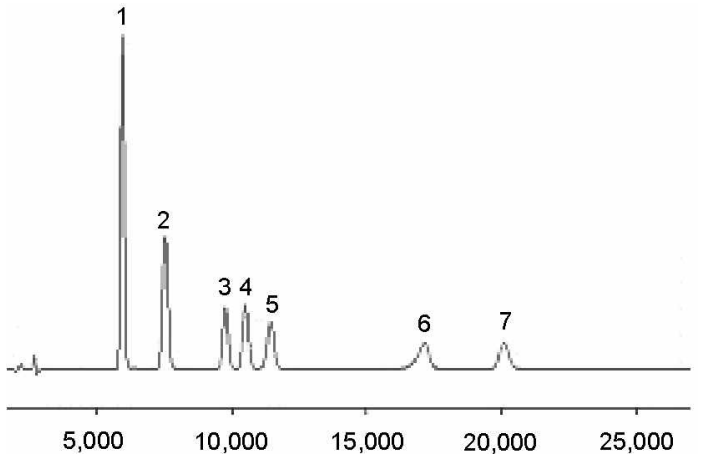

b) Acetonitrile-Water-THF ( $34: 52.8: 13.2$ ) at $1.2 \mathrm{~mL} / \mathrm{min}, 60)^{\circ} \mathrm{C}$

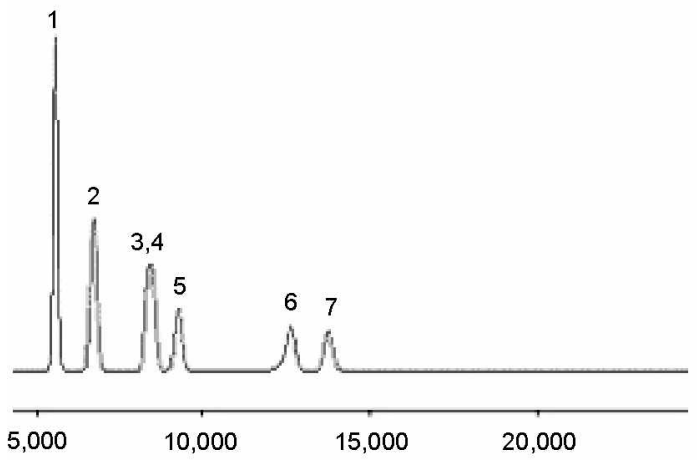

c) Acetonitrile-Water-THF (80:16:4) at $1.0 \mathrm{mLL} / \mathrm{minn}, 35^{\circ} \mathrm{C}$

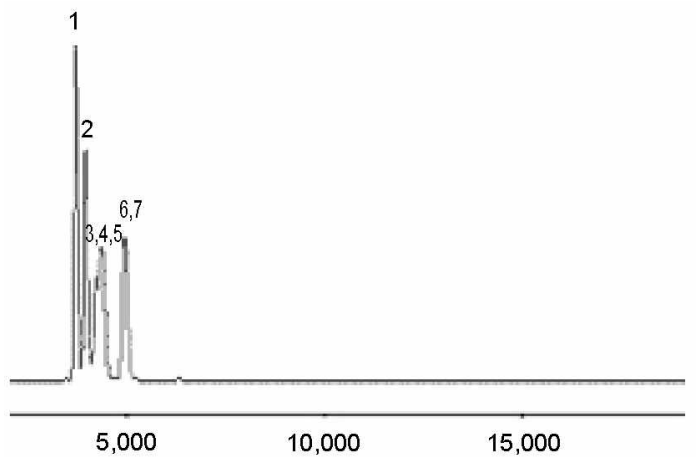

d) Acetonitrile-Water-THF (30:56:14) at $1.0 \mathrm{~mL} / \mathrm{min}, 30^{\circ} \mathrm{C}$

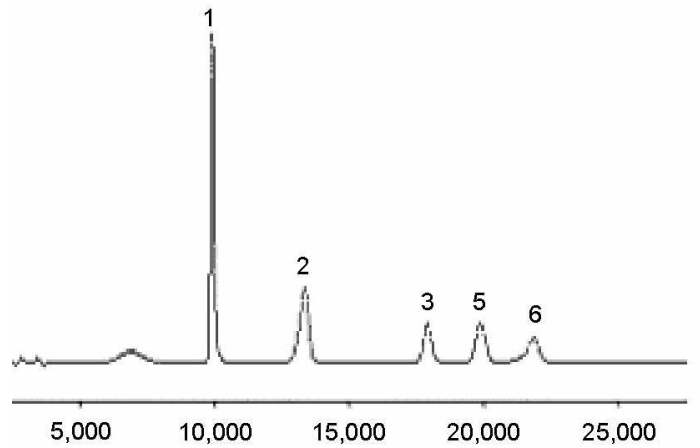

1. Formaldehyde. 2. Acetaldehyde, 3. Acetone, 4. Acrolein. 5. Propionaldehyde. 6. Butyraldehyde. 7. Benzaldehyde

Figure 3. Chromatogram obtained from a standard solution of cartonyl compounds by Mix B types (Acetonitrile + Water + Tetrahydrohuran). optinum condition by comparing the results achieved with analyzed capillary electrochromatography (CEC) and HPLC. The acrolein results did not show linearity between using HPLC and gas chromatography (GC). while the CEC method showed good acrolein peak separation efficiency from acetone and propionaldehyde, demonstrating the superiority of $\mathrm{CEC}^{8}$

The present research showed. however. that satisfactory separation efficiency can be aclueved by controlling only mobile phase composition (acetonitrile. water. THF) and temperature. This validates the practicality of HPLC performance for carbonyl compounds analysis in indoor air pollutants.

Composition ratio check: Figure + shows the peak isolation charactenstics of both isolated and non-isolated peaks. This shows that the averaged value of the diluted standard samples (1/200) was analyzed twice. The analyzed results were not significantly affected by the addition of THF, implicating that there was almost no difference in total peak area. Furthermore. the use of THF made the acetone peak appear earlier than that of acrolein in the intial stage of the expenments. Before the peak separation. the peak area and ratio of the combined materials of acetone and acrolein were deternined. while the peak area and ratio of the respective material was identified after the separation. The ratio of acetone and acrolein before separation accounted for the $21 \%$ of the total area. compared with the ratio of acrolein at $11 \%$ and acetone at $10 \%$

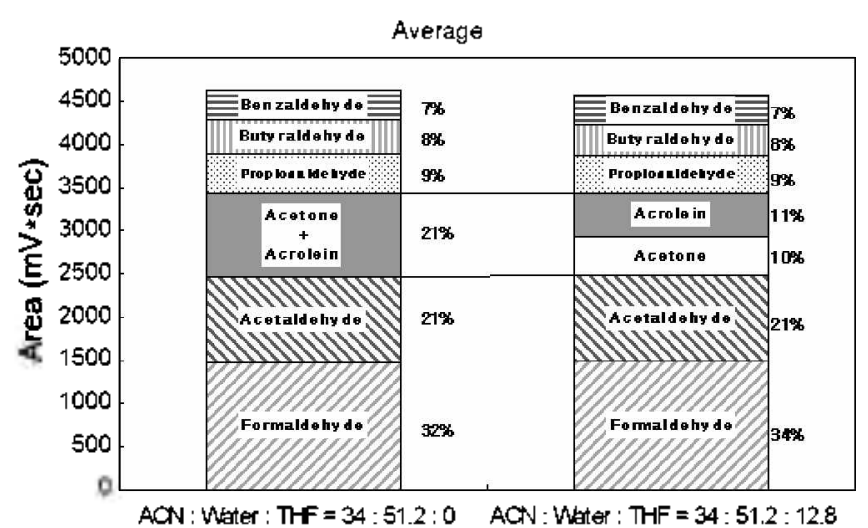

Figure 4. Proportion of carbonyl compounds in standard stock solution for isolated peak and non-isolated peak.

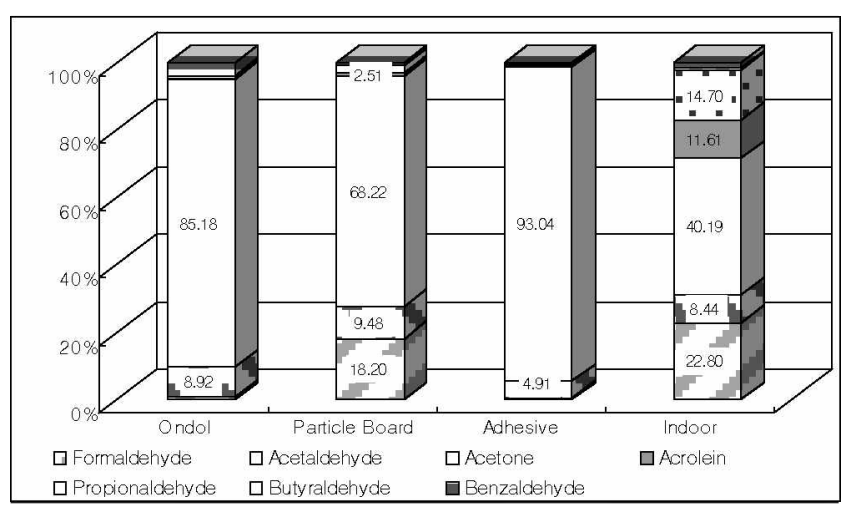

Figure 5. Results of carbonyl compounds emission rates in samples using the DNPH method. 
Application for indoor air quality analysis. Figure 5 presents the results of the emission rates of three building materials. Ondol (Korean underfloor heating). particleboard. and adhesive, and of the indoor emission rate. using the DNPH method.

The chemical emission rate $\left(\mu \mathrm{g} / \mathrm{m}^{3}\right)$ was estimated by analyzing the results of $2 \sim 5$ samples of 4 materials. The small chamber method was used for emission rate testing (Korea Air Cleaning Association). The collected indoor air sample was 167 $\mathrm{mL} / \mathrm{min}$, and the total sample volume was $5 \mathrm{~L}$. Ondol. particleboard. and adhesives. which are available in any market. were used for the experiments. The results are presented according to the averaged values of analysis of 5 Ondol samples. two particleboards and two adhesives. Allowing for the differences in the aldehy'de emission characteristics between the various building materials and indoor spaces. the characteristics of two samples collected in an indoor space were compared.

The indoor samples were collected in the $3^{\text {ril }}$ floor of the UOS Engineering Building. with the average value of the two sample results being determined.

The results of measuring the indoor air quality of new apartment houses nationwide in Korea. performed in 2005 by the National Institute of Environmental Research (NIER). Korea. showed that the acetone-acrolein composition comprised the greatest portion in the carbonyl compounds in 801 household samples from 63 buildings. The next highest level was formaldehy'de followed by buty raldehyde.

As presented in Figure 3 in the average carbonyl compositions emitted from the adhesives and flooring materials, acetone occupied the greatest portion. as previously reported in the results of the research in 2005 .

In indoor spaces. a greater variety of aldehy'de compounds was emitted than in building materials. Similarly in building materials, however, acetone comprised the highest portion. followed by formaldelyde. Acetone and acrolein compositions accounted for about $42 \%$ and $11 \%$. respectively. These results suggest that the use of data analysis to gain an understanding of chemical compositions will be very complicated in non-peak separation.

The building materials - Ondol. particleboard. and adhesives - used in the indoor space and 801 samples collected in the indoor space were carefilly analyzed. and the applicability of the analytical condition for HPLC was fully considered. The proposed methods showed a more decent shape and RT than the existing mobile phase method did.

\section{Conclusion}

In this study the optimum condition for acrolein and acetone peak separation was deternined to be a mobile phase composition of acetonitrile : water : THF of $34: 52.8: 13.2$, a temperature of $32^{\circ} \mathrm{C}$. and a flow rate of $1.2 \mathrm{~mL} / \mathrm{min}$. The calibration curve evaluation result showed decent linearity with $R^{2}$ of 0.997 in the optimum condition. From the reproducibility analysis using the slope of the calibration curve and peak retention area. excellent reproducibility was ascertained on the basis of the RSD values. The area and ratio of the standard samples showed little variation in both peak separation and non-separation cases of acetone and acrolein. The exact peak area was determined by the process of peak separation. Of the total integrated area. acrolein accounted for $11 \%$ and acetone for $10 \%$

An indoor air sample was collected on the $3^{\text {rd }}$ floor of the UOS Engineering Building using the DNPH cartridge for analysis. In the result. acrolein accounted for about $11 \%$ and acetone $42 \%$ out of the total. This confirmed the necessity of separating the acetone and acrolein peaks in order to understand the precise status of each element in the air. Further research with more diverse materials in more various spaces will be required to confirm the accuracy of the method.

Acknowledgments. The authors acknowledge the financial support from the Seoul R\&BD (research and business design) program (Grant no. 10593).

\section{Refelences}

1. NIER 2005, Establishment of New Apartment house, Indoor Air Quality Guideline (II).

2. Ministry of Environment 2005, Indoor Air Quality Managenunet

3. Kelly, T. J.; Smith, D. L.; Satola, J. Enviromental Science and Techmologv $1999,33,81$.

4. Morison, G. C.: Nazaroff, W. W. Enmonmental Science and Techlologv 2002, 36, 2185 .

5. US EPA; Air Risk Infomation Support Center 1994, (Contract NO. 68-D2-(0065).

6. Moon, K. W.; Byeun, S. H.; Choi, D. W.; Lee, E. I.; Oh, E. H.; Kim, Y. W. Korean Joumal of Emmonmental Health Societ, 2006, $32(1), 19$

7. Wang, T. L.; Tong, H. W; Yan, X. Y.; Sheng, L. Q: Yang, J; Liu, S. M. Jomnal of Chromatographia 2005, 62,631

8. Feng, Y. L.; Zhu, J. Joumal of Analytical Sciences 2004, 20, 1691 . 